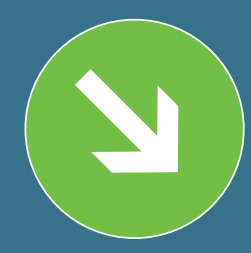

\title{
НОВЫЕ РЕШЕНИЯ ДЛЯ ОПТИМИЗАЦИИ ПРОИЗВОДСТВА НА ЕМ0-2019
}

\author{
ЛюдМИла РАДОНОВА
}

Sandvik Coromant, эксперт в области режущего инструмента и инструментальных систем, примет участие в ЕMO-2019. В рамках выставки компания представит уникальные продукты и новые цифровые решения, такие как облегченная фреза CoroMill® 390 и обновленное ПО CoroPlus® ToolPath для PrimeTurning ${ }^{\mathrm{TM}}$.

Sandvik Coromant использует стенд как площадку для демонстрации новых решений, которые помогут посетителям стенда оптимизировать свои процессы производства. Основным лейтмотивом экспозиции 528 м² станут инновационные цифровые решения для «Индустрии 4.0».

Впервые на стенде компании будет представлено революционное решение для эффективного и надежного сверления отверстий - прорывной инструмент, обладающий отличной работоспособ- ностью при одновременном снижении себестоимости обработки. Он обеспечивает точный диаметр отверстий и снижение уровня шума по сравнению с имеющимся поколением продуктов данного типа.

Облегченная фреза CoroMill $₫ 390$ - еще одна инновация, выполненная методом аддитивных технологий. В сочетании с демпферным адаптером Silent Tools ${ }^{\mathrm{TM}}$ инструмент снижает вибрации при больших вылетах, что приводит к повышению стабильности и производительности.

Помимо режущих инструментов, компания представит цифровые решения, позволяющие соединить процессы проектирования, планирования и обработки, а также обеспечить анализ производственных процессов и их оптимизацию. Различные решения на платформе CoroPlus® от Sandvik Coromant предлагают разные способы интеграции производ-

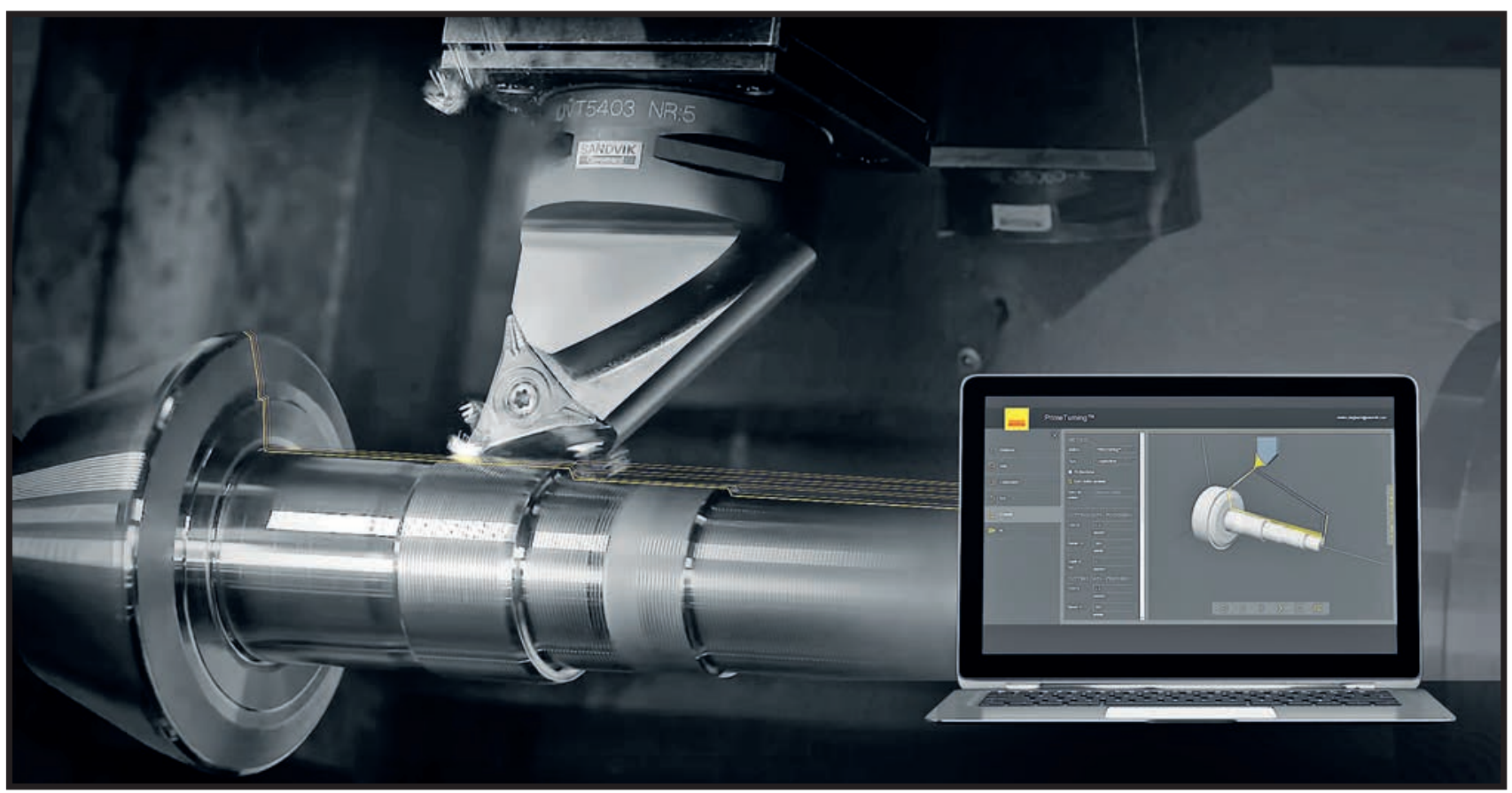

Puc. 1. Обновленное программное обеспечение CoroPlus ${ }^{\circledR}$ ToolPath 
ственного интеллекта на предприятиях для оптимизации процессов и принятия решений на основе фактов. К примеру, уже готовый продукт Coromant Capto ${ }^{\circledR}$ DTH Plus - цифровой приводной инструментальный блок, позволяющий выполнять точное прогнозирование необходимости сервисного обслуживания оснастки.

Обновленное программное обеспечение CoroPlus ${ }^{\circledR}$ ToolPath для PrimeTurningтм, недавно представленной концепции для точения во всех направлениях от Sandvik Coromant, призвано помочь заказчикам, применяющим технологию PrimeTurningтм, ускорить процесс планирования и выполнения операций с использованием этого метода (рис. 1). Теперь ПО позволяет импортировать CAD-модели и проводить 3D-симуляцию с определением столкновений.

Инструменты со встроенными датчиками, такие как Silent Tools ${ }^{\mathrm{TM}}$ Plus, способные отправлять данные прямо на станок - комплексное решение Sandvik Coromant, которое позволяет осуществлять мониторинг и контроль процесса обработки в реальном времени.

Еще одно решение в портфолио CoroPlus® - программное решение CoroPlus $®$ ToolGuide, которое посетители стенда Sandvik Coromant смогут протестировать сами. Это решение дает рекомендации по выбору инструмента и режимов резания в зависимости от указанных пользователем материала заготовки и типа операции. Последняя версия сервиса включает также рекомендации для расточного инструмента.

Sandvik Coromant также презентует новое мобильное приложение «Анализатор износа инструмента» (Tool Wear Analyzer). Если производитель не может определить причины неожиданного износа инструмента, он может сделать фото износа своим смартфоном и сравнить его с типами износа в базе изображений. Приложение также измеряет величину износа, сохраняет изображение и позволяет поделиться с коллегами (рис. 2). Для оптимальной работы приложения используйте микроскоп, устанавливаемый на камеру смартфона.

Более 50 специалистов компании со всего мира, в том числе и из России, проконсультируют посетителей экспозиции и подберут оптимальное производственное решение. Sandvik Coromant предлагает комплексный взгляд на производственный процесс и сотрудничает с производителями станочного оборудования. Поэтому посетители ЕМО найдут решения Sandvik Coromant не только на стенде компании, но и на стендах производителей станков.

17 сентября в конференц-центре EMO пройдет пресс-конференция, посвященная последним технологическим и корпоративным разработкам компании.

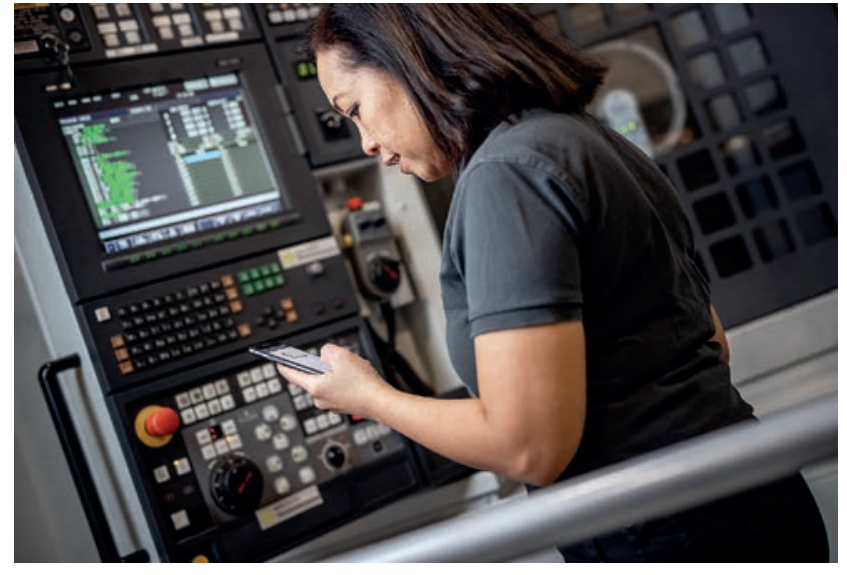

Puc. 2. Работа с мобильным приложением «Анализатор износа инструмента»

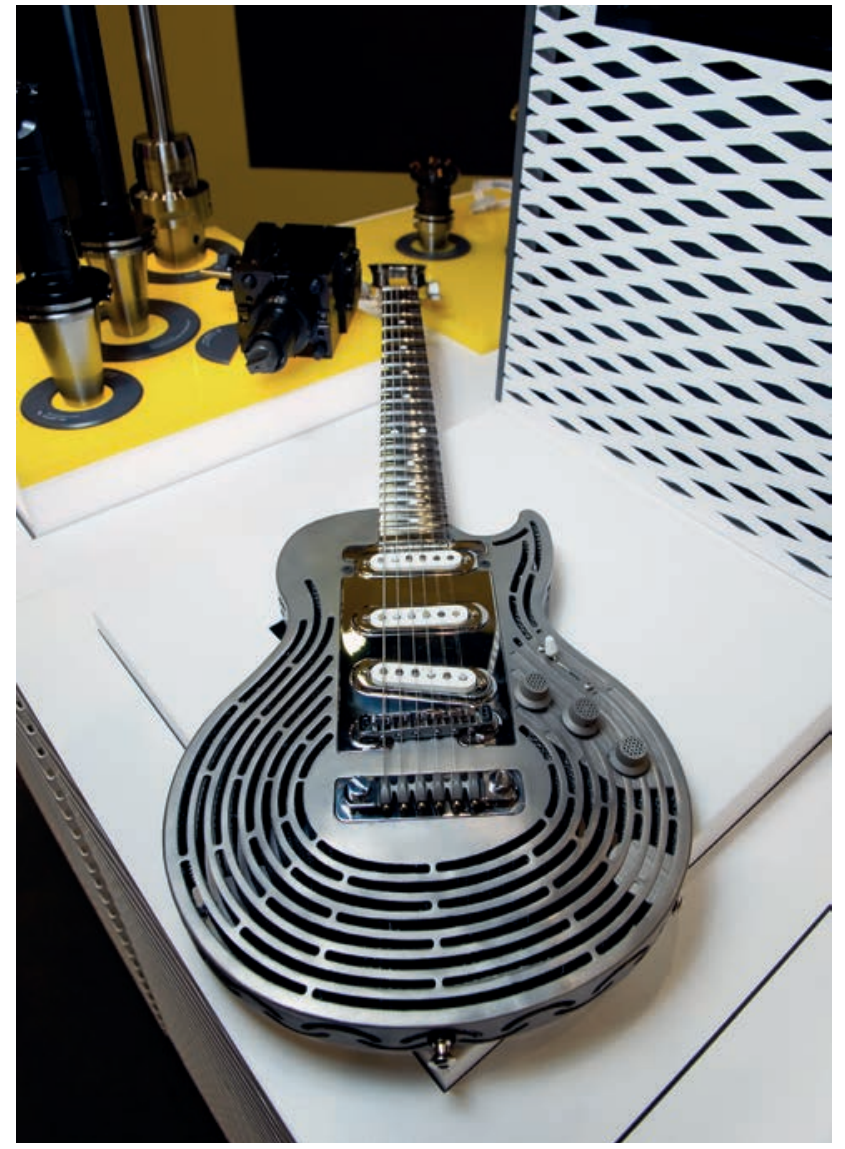

Puc. 3. Ударопрочная гитара Sandvik из титана

Посетители ганноверской выставки также своими глазами смогут увидеть первую в мире ударопрочную гитару Sandvik, выполненную из титана (рис. 3).

РАДОНОВА Людмила -

пресс-служба Sandvik Coromant 